\title{
Trends in Management of Premature Ovarian Failure: The Role of Anti-Mullerian Hormone (AMH) and Tibolone
}

\author{
Omu AE¹, Omu FE², Al-Bader MA¹, and ELbiaa AAM${ }^{1}$ \\ ${ }^{1}$ Department of obstetrics \& gynecology, and physiology, faculty of medicine, Kuwait University Kuwait \& maternity hospital Kuwait \\ ${ }^{2}$ College of nursing, public authority for applied education\& training, Kuwait
}

*Correspondence to: Alexander E. Omu, Department of Obstetrics and Gynaecology, Faculty of Medicine, Health Sciences Center, Kuwait University, Kuwait, E-mail: Omu@hsc.edu.kw

Received: November 26, 2017; Accepted: December 08, 2017; Published: December 23, 2017;

\begin{abstract}
Introduction: Premature Ovarian Failure (POF) is cessation of ovarian functions before the age of 40 years with consequent cessation of menstruation.

Objective of study: This paper aims to resolve two important issues about Premature ovarian Failure (1) To adopt a holistic evaluation of the clinical features and aetiology of POF and (2) To evaluate the outcome of replacement therapy with Tibolone in women with POF.

Patients and methods: Forty-two women seen at the outpatient clinic of Maternity Hospital form the subjects of the study. At the first consultation, clinical evaluation with history, physical examination and investigations were carried out. Blood samples were taken for determination of, Follicle Stimulating Hormone (FSH), Luteinizing Hormone ( $\mathrm{LH})$, prolactin, testosterone and lipid profiles, vitamin D and autoimmune antibodies. Bone density was evaluated with QCT Scan. Ovarian reserve was estimated with serum levels for Anti-Mullerian Hormone.
\end{abstract}

Replacement therapy was with Tibolone $2.5 \mathrm{mg}$ daily for at least 6 months

Results: Climacteric symptoms were common and patients had high serum levels of FSH, LH and low levels of estradiol and AMH. Aetiological factor included bilateral oophorectomy and Ovariectomy, autoimmunity including anti-thyroid and antiovarian antibodies, Chemo-radiotherapy and idiopathic. AMH was undetectable in patients with bilateral ablative ovarian surger and low in the remaining patients. Tibolone was well tolerated by patients with significant relief of vasomotor symptoms $(\mathrm{P}<0.001)$ but no effect on psychological reaction.

Conclusion: POF has multifactorial origin and needs a holistic management

Key words: Premature ovarian failure, Low ovarian reserve, Holistic management

\section{Introduction}

Premature ovarian Failure (POF) is sometimes referred to as Premature Ovarian Insufficiency (POI), Premature Ovarian Aging, Premature Menopause or Early Menopause. Menopause is considered to be premature when it occurs spontaneously in a woman before the age of 40 years. The prevalence of POF is $1 / 10,000$ in women below the age of 20,1/1,000 below 30 and $1 \%$ in women before the age of 40 years $[1,2]$. The European Society of Human Reproduction and Embryology (ESHRE) defined POF as "a clinical syndrome defined by depletion of follicular activity before the age of 40 , characterized by menstrual disturbance (amenorrhea or olig0menorrhea), raised gonadotropins and low estradiol". Its prevalence is said to be about $1 \%$ with long term health consequences [3]. It involves biochemical, physical and emotional perspectives. Physically, it is characterized by primary or secondary amenorrhea for at least four months, sex steroid deficiency and elevated serum gonadotropin concentrations. The diagnosis of premature ovarian failure is based on the finding of oligo/amenorrhea before age 40 associated with follicle-stimulating hormone levels in the menopausal level of $>40 \mathrm{mlU} / \mathrm{L}$ [1-3]. The diagnosis is confirmed by the detection of menopausal FSH levels on at least two occasions a few weeks apart in a woman before the age of 40 years. Screening for associated autoimmune disorders [4] and karyotyping, particularly in early onset disease, constitute part of the diagnostic work up. The classic etiologies are: Turner syndrome, pelvic surgery, radiotherapy and/or chemotherapy. Although new genetic etiologies have been found in the past 10 years, the cause of POF is unknown in more than $75 \%$ of cases [5]. There is no role for ovarian biopsy or ultrasound in making the diagnosis. Regardless of cause, women who experience oestrogen deficiency at an early age before the natural menopause are now recognized to be at increased risk for premature morbidity and mortality [6]. In addition to the loss of fertility, women with POF are at increased risk of developing early atherosclerotic cardiovascular disease in midlife as well as being at increased risk of osteoporotic fractures at an early age. Women with spontaneous premature ovarian failure perceive a need for more aggressive evaluation because the associated estrogen deficiency is a well-established risk factor for osteoporosis. The earlier the loss of normal levels of ovarian hormones, the greater the risk of bone loss.

The role of Anti-mullerian hormone (AMH) in the diagnosis of women with menopause especially Premature Ovarian Failure has 
recently attracted some attention $[7,8]$. In the female, AMH is solely produced by the granulosa cells of preantral and small antral follicles, and regulates ovarian activity and follicular steroidogenesis. Because of this exclusive source of production in the adult female, AMH is a potentially useful marker of ovarian function, and there have been increasing reports on its clinical utility.

Management essentially involves hormone replacement and infertility treatment, the most successful being assisted conception with donated oocytes. The chance to conceive spontaneously after premature ovarian failure is estimated at 5-10 percent $[9,10]$. Embryo cryopreservation, ovarian tissue or oocyte cryopreservation and in vitro maturation of oocytes hold promise in cases where ovarian failure is foreseeable as in women undergoing cancer treatments [11]. In the near future cryopreservation of ovarian tissue will offer some hope to women at risk to develop premature ovarian failure, e.g. women from families with familial premature ovarian failure and women scheduled to undergo chemotherapy or radiotherapy at a young age [11] (Figure 1).

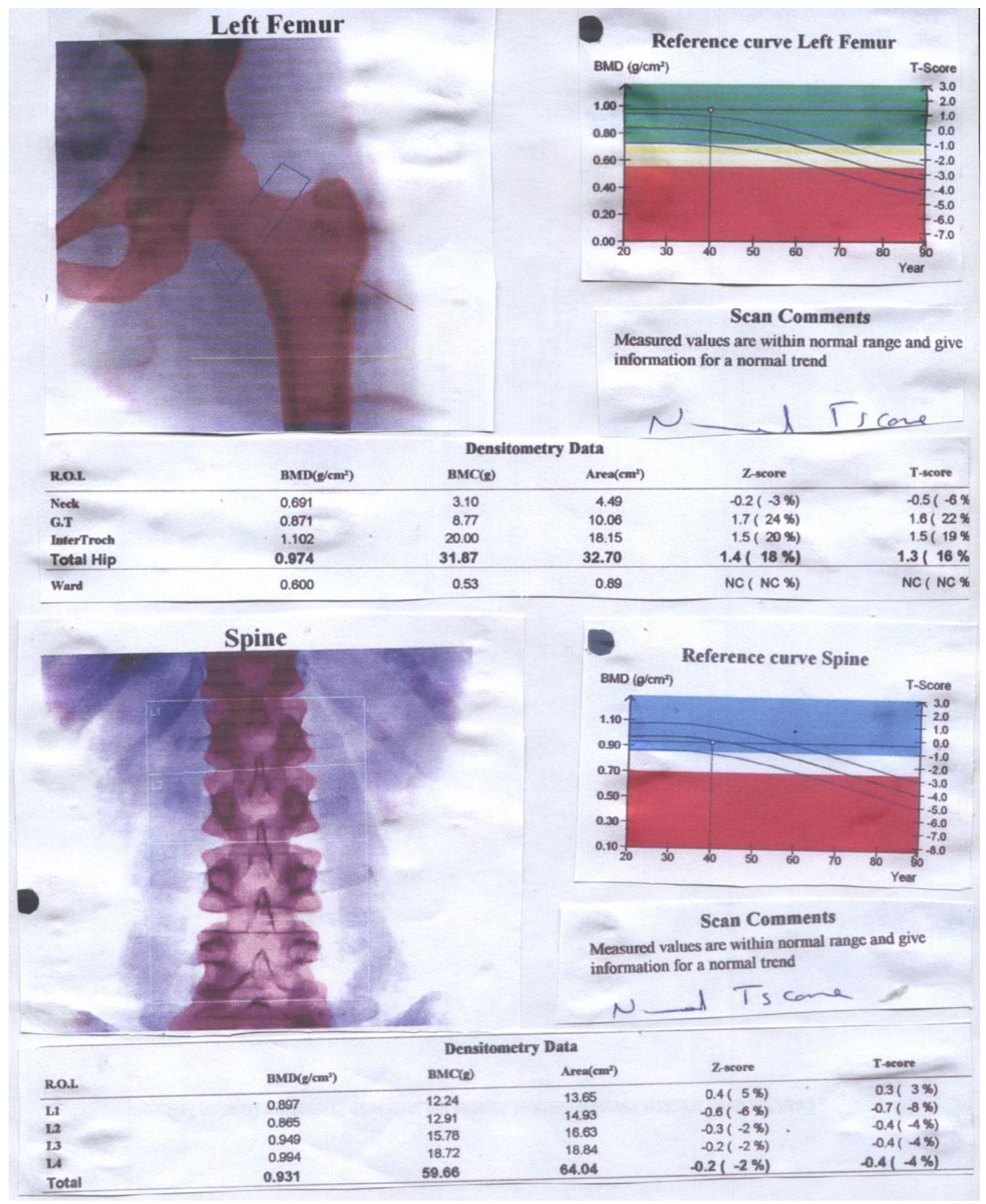

Figure 1. Bone Mineral Densitometry of 36 year old lady with Premature Ovarian Failure 
Most women who experience POF require long term hormone therapy (HT) in order to maintain good overall health. Tibolone is a synthetic hormone and its actions are similar to oestrogen, progesterone and testosterone. It may help to improve mood, help the patient to sleep better, decrease hot flushes and improve general wellbeing. Tibolone may also help sex drive by improving vaginal secretions, increasing free testosterone and mood and it is not associated with an increased risk of breast cancer [5].

Objective of study: This paper aims to resolve two important issues about Premature ovarian Failure (1) To adopt a holistic view in the evaluation of the clinical features and aetiology of POF and the use of Anti-Mullerian Hormone for diagnosis (2) To evaluate the outcome of replacement therapy with Tibolone, in women with POF.

\section{Subjects and Methods}

Forty-two women seen at the outpatient clinic of Maternity Hospital fulfilled the study criteria and were recruited into the study.

\section{Study design}

This is a cross sectional study. Information on the background clinical features leading to premature menopause /ovarian failure were collated and serum levels of Anti-Mullerian Hormone evaluated according to the aetiological factors:

(1) Iatrogenic causes of POF -operation-bilateral oophorectomy or Ovariectomy

(2) Chemo/radio-Therapy

(3) Gradual progression to POF

(4) Auto immune antibodies

The second part of the study investigates the effects of Tibolone $2.5 \mathrm{mg}$ and compared the symptoms of POF posttherapy effects 6 months after, using a scale of 1 to 5 ascendancy in the amelioration of symptoms.

At the first clinic consultation, clinical evaluation which included history pertaining to menstrual cycle characteristics, the occurrence of menopause, use of hormones or other medication, as well as reproductive history, physical examination and investigations, were carried out.

\section{Ethical consideration}

Verbal informed consent was received from all women and the study was approved by the Institutional Review Board of the Maternity Hospital, Kuwait. To obtain the participants' informed consent, the objectives and general procedures of the research was explained to them as well as their right to drop out at any given moment with no ensuing change in the quality of the medical care they would continue to receive.

\section{Investigations}

The investigations included blood samples taken for determination of hormone profile - FSH, LH, prolactin, testosterone and thyroid function test by radioimmunoassay and lipid profile, autoimmune antibodies, Anti-mullerian Hormone and Vitamin $\mathrm{D}_{3}$. Bone density evaluation using QCT Scan was carried out in 17 of the patients.
Hormone profile: Estimation of serum concentration of FSH, LH, Prolactin, Testosterone, Estradiol, TSH and FT4 were carried out with radioimmunoassay.

Lipid profile- The concentration of total and HDL-cholesterol as well as triglyceride were measured directly after 12-14 hours fast. LDLcholesterol concentration were estimated using Friedwald equation thus: LDL-C=Total Cholesterol-HDL- [triglyceride/5].

Auto antibodies- Both anti-thyroid and anti-ovarian were determined by use of indirect immunofluorescence assay.

Anti-mullerian hormone: In order to have an idea of ovarian reserve, serum levels of Anti-Mullerian Hormone were estimated using sandwich ELISA as previously described [12] with the immunosorbent assay from Immunotech Coulter (Marseille, France) with a detection limit of $0.05 \mathrm{ng} / \mathrm{ml}$ and intra and inter-assay coefficients of variation were $<5$ and $8 \%$, respectively.

Vitamin $\mathbf{D}_{3}$ : The 25-hydroxy Vitamin D test, in which the normal concentration of vitamin $\mathrm{D}$ was measured as nanogram per milliliter ( $\mathrm{ng} / \mathrm{ml}$ ) with normal range $20-40 \mathrm{ng} / \mathrm{ml}$.

Genetic testing: Chromosomal analysis of the 15 patients peripheral blood was used for mutational analysis, with the banding technique.

Mammography: Full field digital mammography (FFDM) was used because it uses computerized data recording, tele -reporting and automatic display on monitor of previous results.

\section{Statistical Analysis}

SPSS version 22 was used for the statistical analysis. We only analyze fully completed questionnaires. Comparisons with the Wilcoxon Rank Sum, proportions by Chi Square, and correlations with the Spearman Rank Order was done reported results as mean (SD) or median (range). We considered a p value of less than 0.05 as statistically significant.

\section{Results}

As shown in table 1 , about $38 \%$ of the women with POF were below 30 years and about $60 \%$ below 35 years, and the median age of the women was 28 years, $19 \%$ were single-and 8 of the women could not get married because of POF, while $21.4 \%$ got divorced since the problem of POF started probably as a result of infertility or cessation of menstruation. The women were well educated with $81 \%$ having secondary school education and $19.1 \%$ benefitted from university education. A third of the women had no children, although half of them were married and the mean parity was $1.2 \pm 0.6 ; 14$ (34.2\%) were nulliparous and $22(53.7 \%)$ had 1 to 2 children, thus highlighting a major problem of infertility.

The presenting symptoms are summarized table 2. Climacteric symptoms were common in women with POF with hot flushes $81 \%$, night sweats $38 \%$, vaginal dryness $21 \%$ and dyspareunia $16.7 \%$. Others included itching $11.9 \%$ and depression and anxiety in $38.1 \%$ and $29 \%$ respectively.

Table 3, shows the holistic approach to the investigations. The hormone profile and lipid profile were mandatory in all 42 women. 
The confirmation of menopause is usually through high levels of FSH and LH. All patients had high FSH (52 \pm 4 IU/L) and LH levels $(28 \pm 6)$ in the natural menopausal age and low serum levels of oestradiol. Similarly, baseline lipid profile is necessary for monitoring cardiovascular risks of the patient before commencing them on hormone replacement therapy. In the present study, 6 women (about $14 \%$ ) had elevated total cholesterol and LDL-C.

Table 1: Characteristics of Patients with Premature Ovarian Failure

\begin{tabular}{|c|c|c|c|}
\hline 1. & Age (years) & No. & Percent \\
\hline & $<\mathbf{2 0}$ & 2 & 4.8 \\
\hline & 21-29 & 14 & 33.3 \\
\hline & $30-34$ & 11 & 26.2 \\
\hline & $35-<40$ & 15 & 35.7 \\
\hline \multirow[t]{4}{*}{2.} & Marital Status & & \\
\hline & Single & 8 & 19.1 \\
\hline & Married & 24 & 57.1 \\
\hline & Divorced/widowed & 10 & $23.8(21.4)$ \\
\hline \multirow[t]{5}{*}{3.} & Educational Attainment & & \\
\hline & No formal education & 3 & 7.1 \\
\hline & Primary School & 5 & 11.9 \\
\hline & Secondary School & 26 & 61.9 \\
\hline & University & 8 & 19.1 \\
\hline \multirow[t]{3}{*}{4.} & Parity 0 & 14 & 33.3 \\
\hline & $1-3$ & 25 & 59.5 \\
\hline & $\geq 4$ & 3 & 7.2 \\
\hline
\end{tabular}

Table 2: Investigations Checklist

\begin{tabular}{|l|c|c|}
\hline \multicolumn{1}{|c|}{ Variable } & $\begin{array}{c}\text { Number of Patients } \\
\text { Involved }\end{array}$ & Percentage \\
\hline Hormone profile/ Lipid profile & 42 & 100 \\
\hline Auto immune antibodies & 28 & 66.7 \\
\hline Anti-Mullerian Hormone (AMH) & 24 & 57.1 \\
\hline Mammography & 24 & 57.1 \\
\hline Vitamin $\mathrm{D}_{3}$ & 19 & 45.2 \\
\hline Bone Mineral Density & 17 & 42.0 \\
\hline Genetic Testing (Chromosomal Analysis) & 15 & 35.7 \\
\hline
\end{tabular}

Table 3: Hormone and Lipid Profiles

\begin{tabular}{|c|c|c|c|}
\hline 1. & Hormone Profile & & Normal Range \\
\hline & LH (1U/L) & $28 \pm 6$ & $10.9-58.7$ \\
\hline & FSH(1U/L) & $52 \pm 4$ & 16-114 \\
\hline & Testosterone (nmol/L) & $1.2 \pm 0.6$ & $0.22-2.9$ \\
\hline & Prolactin (mlu/L & $31.5 \pm 75$ & $72-511$ \\
\hline & Estrogen (pmol/L) & $10.5 \pm 40$ & 73-324 \\
\hline & FT4 & $14 \pm 3.2$ & $12-22$ \\
\hline \multirow[t]{5}{*}{2.} & Lipid & & \\
\hline & T. Cholesterol (mmol/L) & $4.4 \pm 1.2$ & $3.1-5.2$ \\
\hline & HDL-C (g/dl) & $2.8 \pm 0.8$ & $1.01-2.49$ \\
\hline & LDL-C (mmol/L) & $3.2 \pm 1.2$ & $3.9-4.9$ \\
\hline & Triglyceride (mIU/L & $2.1 \pm 0.8$ & $0.34-2.28$ \\
\hline 3. & Vitamin $D_{3 \mathrm{ng} / \mathrm{ml}}$ & $10.6 \pm 4.2$ & $20-40$ \\
\hline
\end{tabular}

As shown in table 4, ablative operations with removal of the ovaries (Oophorectomy and ovariectomy) was the commonest single cause of POI. Two women had POF at the age of 18 and 19 years respectively as a result of bilateral torsion of the ovarian cyst and ischaemia and gangrene formation. Another 2 had ruptured inflammed appendix mass with resultant generalized morbid pelvic adhesions with amalgamation of both ovaries. At operation, the ovaries were inadvertently removed. A 21 year old women that had malignant thecoma involving both ovaries, had them removed with extensive metastasis. It is of paramount importance to distinguish between premature ovarian failure (POF) and premature menopause. This is why we evaluated the serum levels of AMH in the four groups as shown in table 4 which summarizes the causative factors of POF: (1) POF from ablative operation of bilateral oophorectomy or ovariectomy (2) POF from gonadotoxicity of chemotherapy / radiotherapy (3) POF from autoimmunity from anti-thyroid and anti-ovarian antibodies and (4) idiopathic POF which in $48 \%$ of the women. For comparison, an internal control group of ten women with regular periods was recruited and also had serum AMH assays as shown in figure 2. serum Anti-mullerian hormone was undetectable in group 1, detectable in group 2 at very low levels $(\mathrm{p}<0.05)$. There was significant difference between groups 3 and $4(\mathrm{P}<0.01)$. Although conditions like Turner's Syndrome and Trisomy 21 were excluded from the present study, Genetic testing was carried out in 15 women with POF under 30 years of age. The only finding was " $46, \mathrm{XX}, 9$ (phqh, normal variant" which was normal for the female.

Table 4: Aetiological Factors of Premature Ovarian Failure

\begin{tabular}{|l|c|c|}
\hline & No. & Percent \\
\hline Operation with removal of ovaries & 8 & 19.0 \\
\hline Chemotherapy and Radiotherapy & 7 & 16.7 \\
\hline Autoantibodies & 7 & 16.7 \\
Thyroglobulin Antibodies & 3 & \\
Thyroid Microsomal Antibodies & 2 & \\
Antiovarian Antibodies & 2 & \\
\hline Idiopathic & 20 & 47.6 \\
\hline
\end{tabular}

The use of Tibolone for replacement therapy, was well tolerated by majority of the women. The only side effect was break-through which was mainly due to inability of the woman to take the drug as advised. Concerns about deep vein thrombosis (DVT) and stroke made the team monitor Tibolone with lipid profile. No abnormality was detected.

In Table 5, the outcome of replacement therapy is evaluated using the scale of 1 (No change) to 5 (Total improvement). Hot flushes, night sweats, vaginal dryness, dyspareunia and vulva itching have significant improvement and total elimination of symptoms. Urinary frequency has some improvement but not significant. Tibolone has no effect on emotional reactions like depression and anxiety. 


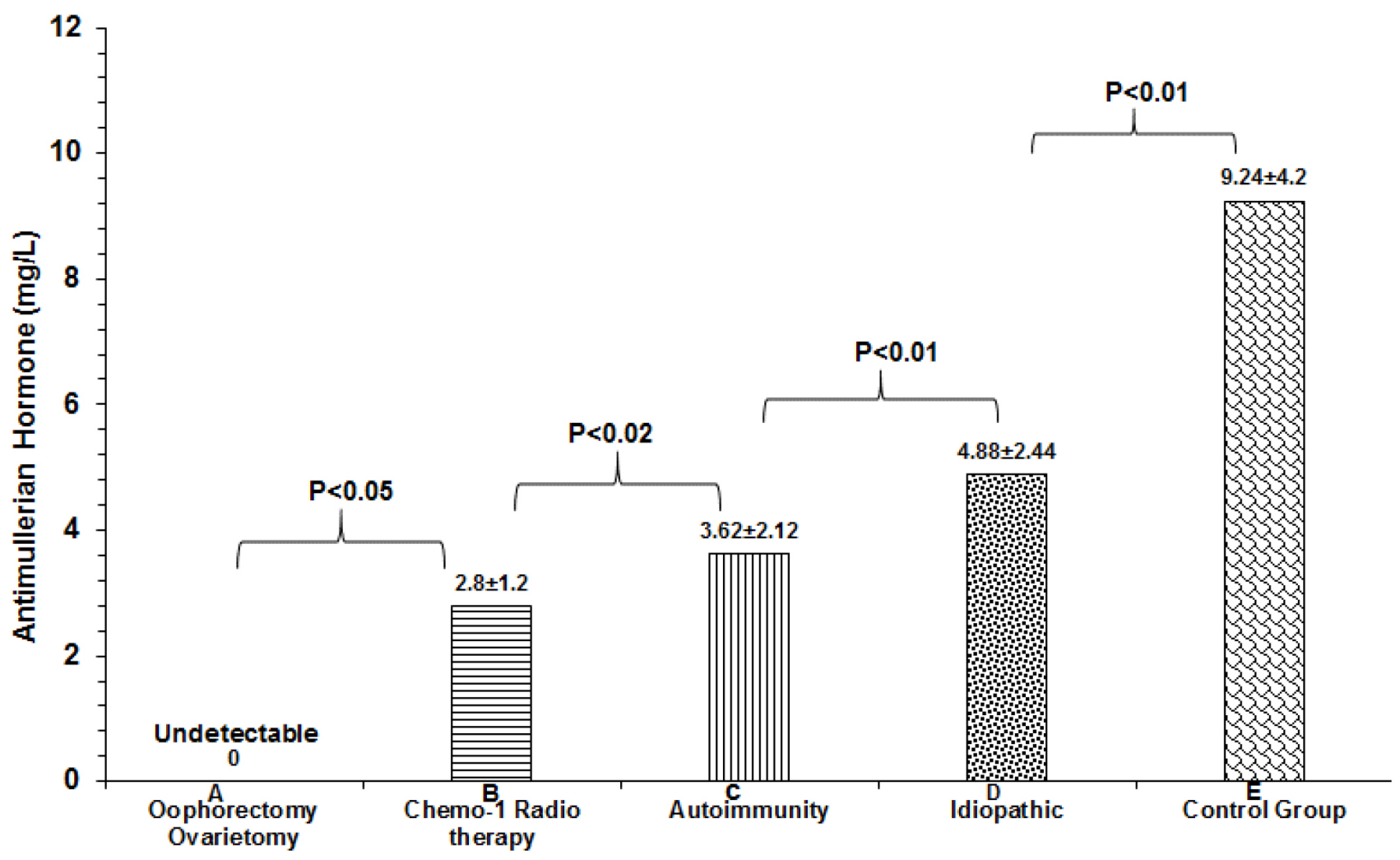

Aetiological Factors of Premature Ovarian Failure
A vs $\mathrm{E} P<0.001$
$\mathrm{B}$ vs $\mathrm{E} \mathrm{P}<0.01$
$\mathrm{C}$ vs $\mathrm{E} \mathrm{P}<0.01$
$\mathrm{V}$ vs $\mathrm{E} \mathrm{P}<0.02$

Figure 2: Comparative serum levels of AMH

Table 5: Effects of Replacement Therapy with Tibolone.

\begin{tabular}{|c|c|c|c|c|c|c|c|c|c|}
\hline Symptoms & No of Patients & Percent & 1 & 2 & 3 & 4 & 5 & CR & P value \\
\hline Hot flushes & 34 & 81.0 & 0 & 0 & 5 & 11 & 18 & 0.824 & 0.001 \\
\hline Night Sweat & 16 & 38.1 & 0 & 0 & 2 & 4 & 10 & 0.642 & 0.01 \\
\hline Vaginal dryness & 9 & 21.4 & 0 & 1 & 1 & 2 & 5 & 0.482 & 0.02 \\
\hline Dyspareunia & 7 & 16.7 & 0 & 1 & 2 & 1 & 3 & 0.412 & 0.05 \\
\hline Vulva itching & 5 & 11.9 & 0 & 1 & 0 & 2 & 2 & 0.386 & 0.05 \\
\hline Urinary Frequency & 5 & 11.9 & 2 & 1 & 2 & 0 & 0 & 0.122 & 0.08 \\
\hline \multicolumn{10}{|l|}{ Emotional R } \\
\hline Depression & 16 & 38.1 & 6 & 4 & 6 & 0 & 0 & 0.021 & 1.02 \\
\hline Anxiety & 12 & 28.6 & 6 & 4 & 1 & 1 & 0 & 0.011 & 1.12 \\
\hline
\end{tabular}

$1=$ No Change, $2=$ Little improvement, $3=$ Moderate improvement, $4=$ great improvement, $5=$ Total improvement 


\section{Discussion}

The present study has shown that patient with POI are normally developed individuals well prepared for exigencies of life with appropriate education and social marital setting. However, a diagnosis of POI, has both short and long term health problems. In the short term, many of them have hot flushes, insomnia and problems of oestrogen deficiency like dyspareunia and bladder problems [1]. Long term health concerns as a result of oestrogen deficiency may include cardiovascular disorders and osteoporosis [13].

Auto-immune diseases with autoantibodies have been associated with Premature ovarian Insufficiency in the present study. Many other autoimmune conditions have been similarly implicated. They include Endocrine diseases such as hypothyroidism,addison's disease,, hypophysitis, hypoparathyroidism, and Type 1 diabetes, all in association with their autoantibodies [14-17]. In addition there are also non-endocrine conditions like Pernicious anaemia, Myasthenia gravis, Chronic candidiasis (in type 1 autoimmune polyglandular failure syndrome), Idiopathic thrombocytopenic purpura, Vitiligo, Alopecia, Autoimmune haemolyticanaemia, Systemic lupus nephritis, Crohn's disease, Sjögren's syndrome, Rheumatoid arthritis, Primary biliary cirrhosis, Coeliac disease, Chronic active hepatitis [18,19].

Genetic basis of Premature ovarian Failure was not revealed in the present study, may be because of the small number of women with that had genetic testing. They may include 45X0 (Turners syndrome) that gives rise to gonadal dysgenesis and primary amenorrhoea. Blocking mutations of FSH receptors leads to primary Amenorrhoea. Fragile X Occurs when number of trinucleotide repeats is in excess of 200 and gene transcription fails and FMRI (Xq27.3) protein is not expressed with increased prevalence of POF [20]. Other candidate genes for POI Chromosome 3-long arm (syndrome of blepharophimosis, ptosis and POI). The absence of Connerin 37 between ovum and granulosa cells, leads to infertility in mice [21]. The present study has clearly demonstrated that Tibolone relieves vasomotor symptoms such as hot flushes, night sweats, vaginal dryness and dyspareunia. Tibolone is a synthetic hormone and its actions are similar to oestrogen, progesterone and testosterone [5]. It may help to improve mood, help you sleep better, decrease hot flushes and improve general wellbeing. Tibolone may also help sex drive by improving vaginal secretions, increasing free testosterone and mood. Tibolone is not associated with an increased risk of breast cancer, in women without breast cancer [5].

Conversely, Tibolone has little effect on urinary symptoms like frequency and urge incontinence and psychological reactions such as depression and anxiety, which are common in in patients diagnosed with premature ovarian failure.

Managing menopause in women with cancer involves a number of options (Shover et al). These include lifestyle changes, which can help reduce depression, anxiety, cardiovascular and osteoporosis risks, psychological support and medication

Counselling and education to diagnose impending POF presenting with irregular menstrual periods. And before chemotherapy and/ or radiotherapy, you should investigate your options for trying to preserve eggs for conception. There are a number of options including, egg preservation, embryo freezing, ovarian preservation and ovarian biopsy and freezing [22].

\section{Limitations of the study}

(1) Small sample. There is need for larger sample size with high cronbach factor.

(2) Not all 42 women benefitted from all the investigations.

\section{Conclusion}

This study has articulated a new paradigm in the management of POF with holistic attitude towards diagnosis and treatment with monitoring of treatment.

\section{References}

1. Omu AE, Al-Qattan N. Premature menopause. Sing J. Obstet Gynaecol 1996; 27 : 23-8

2. Conway G.S. Premature Ovarian failure. Curr Opin Obstet Gynecol 1997; 9: 202 - 206

3. ESHRE (2015) Management of women with Premature Ovarian Insufficiency: Guideline of the European Society of Human Reproduction and Embryology; 8-16.

4. Christin-Maitre S, Braham R.General mechanisms of premature ovarian failure and clinical check-up. Gynecol Obstet Fertil. 2008; 36: 857-61.

5. Vandborg M, Lauszus F. F., Premature ovarian failure and pregnancy Arch Gynecol Obstet. 2006; 273: 387-8.

6. van Kasteren YM. Premature ovarian failure Ned Tijdschr Geneeskd.2000; 144: $2142-6$.

7. Goswami D, Conway GS. Premature ovarian failure. Horm Res. 2007; 68(4): 196-202.

8. Groff AA, Covington SN, Halverson LR, Fitzgerald OR, Vanderhoof V, Calis K, Nelson LM. Assessing the emotional needs of women with spontaneous premature ovarian failure. Fertil Steril. 2005; 83: 1734-41.

9. Petras, K. (1999) The Premature Menopause Book: When the change of life comes too early. (1 ${ }^{\text {st }}$ edi) HarperCollins, New York. USA.

10. DeAngelo D (2000) Sudden Menopause: Restoring Health and Emotional WellBeing. (1 ${ }^{\text {st }}$ edi) Hunter House, Salt Lake city, USA.

11. Sterling E W \& Best-Boss A (2010) Before your Time: The Early Menopause Survival Guide. (1 $1^{\text {st }}$ edi). Simon \& Schuster, New York, USA.

12. Sterling, E. W. \& Nelson, L.M. (2011). From Victim to Survivor to Thriver: Helping Women with Primary Ovarian Insufficiency integrate Recovery, Self-Management, and Wellness. Semin Reprod Med. 29 (4): 353-361. Doi: 10.1055/s-0031-128092.

13. Rafique, S., Sterling, E. W., Nelson, L. M. (2012).A New Approach to Primary Ovarian Insufficiency.Obstet GynaecolClin North America 39(4): 567-586.Doi: 10.1016/j.ogc.2012.09.007

14. Monnier, P. (2013). Primary Ovarian Insufficiency: The Words to Say. Reproductive endocrinologist Winter 2013/14

15. Judge, T. A., Locke, E. A. \& Durham, C. C. (1997) The dispositional causes of job satisfaction: A core evaluations approach. Research in Organizational Behavior.19: 151-188

16. Bandura, A. (1977). Self-efficacy: Towards a Unifying Theory of Behavioral Change. Psychological Review, Vol. 84, No. 2, 191-215.

17. Klein, J. \& Wasserstein-Warnet, M (1999).Predictive validity of the locus of control test in selection of school administrators.Journal of Educational Administrators, 38(1), 7-24. http: //dx.doi.org/10.1108/09578230010310957

18. Burish, T. G., Carey, M. P., Wallston, K. A., Stein, M. J., Jamison, R. N. \& Lyles, J. N. (1984). Health Locus of control and chronic disease: An external orientation may be advantageous. Journal of Social and Clinical Psychology. Vol 2, No 4, pp.326-332.

19. Smith, E. R..\& Mackie, D. M. (2007). Social Psychology (3rded) Hove: Psychology press

20. Maslow, A. H. (1987). Motivation and Personality ( $\left.3^{\text {rded }}\right)$ New York: Harper \& Row.

21. Wickman, S. A. \& Campbell, C. (2003). An Analysis of how Carl Rogers enacted clientcentered conversation with Gloria. Journal of counseling \& development 81: 178-184 
22. Schacter, D. L., Gilbert, D. T. \& Wegner, D. M. (2009). Self Esteem. Psychology ( $\left.2^{\text {nded }}\right)$ Barnes \& Noble.New York: Worth publishers.

23. Baumeister R \& Tierney J (2011). Willpower: Rediscovering the Greatest Human Strength. Penguin press.

24. Bouchard G (2003) Cognitive Appraisals, neuroticism, and openness as correlates of coping strategies: An integrative model of adaptation to marital difficulties. Canadian Journal of Behavioural Science, Vol 35 (1) http://dx.doi.org/10.1037/ h0087181.

25. Costa , P T; \& McCrae, R R., (1980) Influence of Extraversion and Neuroticism on Subjective Well-Being: Happy and Unhappy people. Journal of Personality and Social Psychology, Vol 38. 668-678.

26. Ventura J L, Fitzgerald O R; Koziol D E, Deloris E, et al (2007) Functional well-being is positively correlated with spiritual well-being in women who have spontaneous premature ovarian failure. Fertility and Sterility, Vol.87 (3): 584-590, doi: 10.1016/j.fertnstert.2006.07.1523.

27. Stanford Chronic Disease Self-Management Study. Psychometrics reported in: Lorig K, Stewart A, Ritter P, González V, Laurent D, \& Lynch J, Outcome Measures for Health Education and other Health Care Interventions. Thousand Oaks CA: Sage Publications, 1996, pp.24-25,41-45.

28. Shuster L T, Rhodes D J,. Gostout B S,Grossardt B R, RoccaW A. Premature menopause or early menopause: long-term health consequences. Maturitas. 2010; 65: $161-165$.

29. Persani L, Rossetti R, Cacciatore C, Bonomi M. Primary Ovarian Insufficiency: X chromosome defects and autoimmunity. J Autoimmun. 2009; 33: 35-41.

30. Mlčochova H, Hořejši Martinek $J$ J. Vetešnikova-Koubova R.\&Halaška M. Treatment of autoimunne ovarian damage in adolescent girls. Neuroendocrinology Letters 2005. No.2 Vol.26,
31. Santoro N. Mechanisms of premature ovarian failure Ann Endocrinol 2003; 64: $87-92$.

32. Kauffman RP, Castracane VD. Premature ovarian failure associated with autoimmune polyglandular syndrome: patophysiological mechanism and future fertility. J Women's Health (Lachmt) 2003; p. 513-20.

33. Jacobs PA Fragile X-syndrome. J Med Genet 1991; 28: 809-810

34. Conway G S.,.Payne1 N N, Webb J, Murray A and.Jacobs PA. Fragile X premutation screening in women with premature ovarian failure. Human Reproduction 1998; 13: $1184-1187$

35. Carmody et al. Mindfulness training for coping with hot flashes: Results of a randomized trial. Menopause. 2011; 18(6): 611-620. doi: 10.1097/ gme.0b013e 318204a05c

36. Ikeme ACC, Okeke TC, Akogu SPO, Chinwuba N. Knowledge and perception of menopause and climacteric symptoms among a population of women in Enugu, South East, Nigeria. Ann Med Health Sci Res. 2011; 1: 31-6.

37. Dolleman et al. Anti-Müllerian hormone is a more accurate predictor of individual time to menopause than mother's age at menopause. Hum. Reprod. (2014; 29: $584-$ 591. doi: 10.1093/humrep/det446 First published online: January 15, 2014

38. Luborsky J. Ovarian Autoimmune Disease and Ovarian auto antibodies. J. Women Health and Gender Based Medicine 2002; 11: 585-599.

39. Sayakhot et al. Potential adverse impact of ovariectomy on physical and psychological function of younger women with breast cancer. Menopause, 2011; 18: 786-793.

40. Broer SL, Eijkemans MJ, Scheffer GJ, van Rooij IA, de Vet A, Themmen AP, Laven JS, de Jong FH et al Anti-mullerian hormone predicts menopause: a longterm follow-up study in normoovulatory women. J Clin Endocrinol Metab. 2011; 96: 2532-9.

\section{Citation:}

Omu AE, Omu FE, Al-Bader MA, and ELbiaa AAM (2018) Trends in Management of Premature Ovarian Failure: The Role of Anti-Mullerian Hormone (AMH) and Tibolone. Integr Gyn Obstet $J$ Volume 1(1): 1-7 